\title{
Silk Fibroin Nanofiber. Electrospinning, Properties, and Structure
}

\author{
So Hyun KIM, Young Sik NAM, Taek Seung LEE, and Won Ho PARK ${ }^{\dagger}$ \\ Department of Textile Engineering, College of Engineering, Chungnam National University, Daejeon 305-764, Korea
}

(Received October 18, 2002; Accepted December 14, 2002)

\begin{abstract}
An electrospinning process was used to fabricate silk fibroin (SF) nanofiber nonwovens for wound dressing applications. The electrospinning of regenerated SF was performed with formic acid as a spinning solvent. For crystallization, as-spun SF nanofiber nonwovens were chemically treated with an aqueous methanol solution of $50 \%$. The morphology, porosity and conformational structures of as-spun and chemically treated SF nanofibers were investigated by scanning electron microscopy (SEM), mercury porosimetry, wide angle X-Ray diffraction (WAXD), attenuated total reflectance infrared spectroscopy (ATR-IR), solid state ${ }^{13} \mathrm{C} \mathrm{CP/MAS} \mathrm{nuclear} \mathrm{magnetic} \mathrm{resonance} \mathrm{(NMR)} \mathrm{spectroscopy.}$ SEM micrograph showed that the electrospun SF nanofibers had an average diameter of $80 \mathrm{~nm}$ and a distribution in diameter ranging from 30 to $120 \mathrm{~nm}$. The porosity of as-spun SF nanofiber nonwovens was $76.1 \%$, indicating it was highly porous. Conformational transitions of the as-spun SF nanofibers from random coil to $\beta$-sheet by aqueous methanol treatment occurred rapidly within $10 \mathrm{~min}$, confirmed by solid-state ${ }^{13} \mathrm{C}$ NMR, ATR-IR, and X-Ray diffraction.

KEY WORDS Silk Fibroin / Electrospinning / Nanofiber / Nonwovens / Conformation / Porosity / $\beta$-Sheet / Random Coil /
\end{abstract}

Silk as a typical fibrous protein is produced by a variety of insects including silkworm. Among the native silk proteins, the silkworm silk, mostly that of the domesticated Bombyx mori, has been used as high-quality textile fiber and suture for a long time. B. mori silk consists of two types of proteins, fibroin and sericin. Fibroin is the protein that forms the filaments of silkworm silk and gives silk its unique physical and chemical properties. ${ }^{1}$ Sericins are the group of gummy proteins which bind the fibroin filaments. Silk fibroin (SF) can be used in various forms, such as gels, powders, fibers, or membranes, depending on application..$^{2-5}$ Besides its utility as a textile fiber, many researchers have recently investigated SF as one of candidate materials for biomedical applications because it has several useful properties including good biocompatibility, good oxygen and water vapor permeability, biodegradability, and minimal inflammatory reaction. ${ }^{6-8}$ Practically, SF has been used in various fields such as cosmetics, medical materials for human health, and food additives.

Recently, much attention has been paid to electrospinning process as an unique technique because it can produce polymer nanofibers with diameter in the range from several micrometer down to tens of nanometers, depending on the polymer and processing conditions. In electrospinning, a high voltage is applied to create electrically charged jets of a polymer solution. These jets dry to form nanofibers, which are collected on a target as nonwovens. These nanofibers are of considerable interest for various kinds of applications, because they have several unique properties such as high specific sur- face area and high porosity. Examples are fiber membranes for filter applications, ${ }^{9}$ biomedical applications such as wound dressings and scaffolds for tissue engineering, ${ }^{10,11}$ sensing applications, ${ }^{12,13}$ and fiber templates for the preparation of functional nanotubes. ${ }^{14,15}$

The ultimate aim of this study is to develop wound dressings composed of the electrospun SF nanofibers. Up to date, some attempts to artificially spin silk protein fibers have been reported. ${ }^{16-20}$ There has also been a preliminary report of electrospun spider silk nanofibers. ${ }^{19}$ In the present paper, we describe how we have adapted the electrospinning process to fabricate an engineered matrix composed of SF nanofibers for use in tissue engineering scaffolds or wound dressings. In addition, the chemical treatment to crystallize the as-spun $\mathrm{SF}$ nanofibers was conducted. Solid-state ${ }^{13} \mathrm{C} \mathrm{CP} / \mathrm{MAS}$ nuclear magnetic resonance (NMR), wide-angle X-Ray diffraction (WAXD), ATR-IR were used to investigate the conformational structure of as-spun and chemically treated SF nanofibers.

\section{EXPERIMENTAL}

\section{Preparation of Regenerated SF and Electrospinning Solution}

Raw silk fibers were degummed twice with $0.5 \%(\mathrm{w} / \mathrm{w}) \mathrm{NaHCO}_{3}$ solution at $100{ }^{\circ} \mathrm{C}$ for $30 \mathrm{~min}$ and then rinsed with warm distilled water. Degummed silk (silk fibroin, $\mathrm{SF}$ ) was dissolved in a ternary solvent system of $\mathrm{CaCl}_{2} / \mathrm{CH}_{3} \mathrm{CH}_{2} \mathrm{OH} / \mathrm{H}_{2} \mathrm{O}(1 / 2 / 8$ in mol ratio) at $70^{\circ} \mathrm{C}$ for $6 \mathrm{~h}$. After dialysis with cellulose tubular

†To whom correspondence should be addressed (Fax: +82-42-823-3736, E-mail: parkwh@cnu.ac.kr). 
membrane (Sigma Co., 250-7u) in distilled water for $3 \mathrm{~d}$, the SF solution was filtered and lyophilized to obtain the regenerated SF sponges. The SF solutions for electrospinning were prepared by dissolving the regenerated SF sponges in 98\% formic acid (Aldrich Co.) for $3 \mathrm{~h}$. Viscosity of SF solution was measured using a Brookfield viscometer (Model LVDVE 230). Electrospinning concentrations of SF solutions was in the range from 6 to $15 \mathrm{wt} \%$.

\section{Electrospinning of SF Solution}

In the electrospinning process, a high electric potential was applied to a droplet of SF solution at the tip (ID $0.495 \mathrm{~mm}$ ) of a syringe needle, as shown in Figure 1. The electrospun nanofibers were collected on a target drum which was placed at a distance of $\sim 7 \mathrm{~cm}$ from the syringe tip. A voltage of $15 \mathrm{kV}$ was applied to the collecting target by a high voltage power supply. The flow rate of polymer solution was $1.5 \mathrm{~mL} \mathrm{~h}^{-1}$.

\section{Chemical Treatment of Electrospun SF Fibers}

The as-spun SF nanofibers were crystallized and insolubilized by immersing in $50 \%(\mathrm{v} / \mathrm{v})$ aqueous methanol solution for 10 to $60 \mathrm{~min}$ at room temperature, and dried under vacuum for $24 \mathrm{~h}$.

\section{Characterization}

Scanning electron microscope (SEM, Hitachi S2350) was used to investigate the macroscopic morphology/surface texture of electrospun SF fibers. ATRIR spectra of electrospun SF fibers were obtained with a Travel IR in the spectral range of $4000-400 \mathrm{~cm}^{-1}$. WAXD experiments were performed on a Rigaku finefocus fixed tube generator with $\mathrm{Ni}$-filtered $\mathrm{Cu}-K \alpha$ radiation $(\lambda=0.154 \mathrm{~nm})$, and a flat-film camera with pinhole collimation. Irradiation conditions were $40 \mathrm{kV}$ and $30 \mathrm{~mA}$. The ${ }^{13} \mathrm{C}$ solid-state CP/MAS NMR spectra of the electrospun SF fibers were obtained on a Bruker

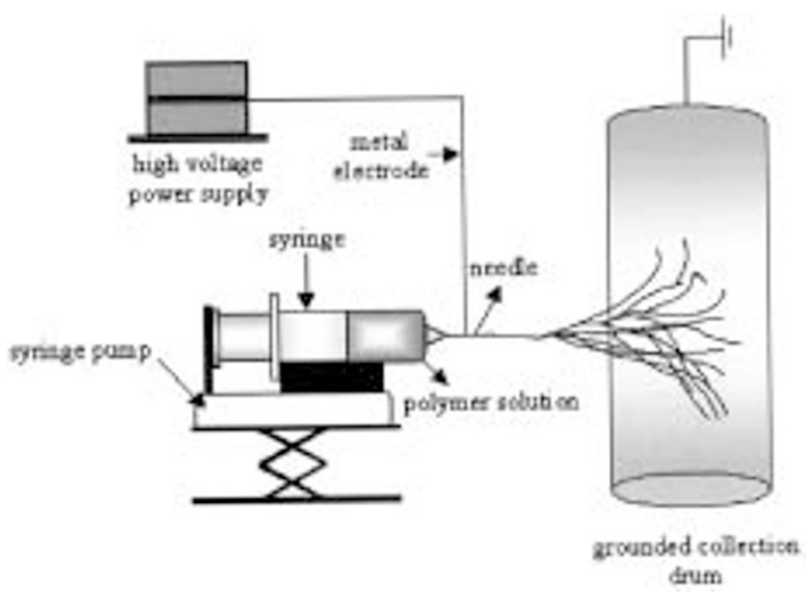

Figure 1. Schematic diagram of electrospinning system.
DSX $400 \mathrm{MHz}$ solid NMR spectrometer using a crosspolarization pulse sequence and with magic-angle spinning at 5 or $6.5 \mathrm{kHz}$.

Pore properties in the interfiber pore region were determined by mercury intrusion technique using a AutoPore III mercury porosimeter (Micromeritics Instrument Co.). The $50 \mu \mathrm{m}$ thick electrospun nonwoven was cut into $1 \mathrm{~cm} \times 2 \mathrm{~cm}$ rectangular shapes and weighed. A sample was placed in the cup of the penetrometers ( $£$ $\mathrm{s} / \mathrm{n}-14,3$ Bulb, 0.412 Stem, Powder), which was closed by tightening the cap. The penetrometer, along with a sample, was sent into the pressure chamber of the porosimeter for measurement of pore properties.

\section{RESULTS AND DISCUSSION}

\section{Preparation and Morphology of Electrospun SF Nanofibers}

While the raw silk fibroin was insoluble in formic acid because of highly ordered intermolecular hydrogen bonds, the regenerated SF was readily soluble in formic acid. The regenerated SF solution obtained by dissolving in formic acid was transparent. However, formic acid used for the preparation of SF solution is a moderate strong acid $\left(\mathrm{pKa}=1.8 \times 10^{-4}\right)$. The viscosity of the SF solution was measured to observe the effect of formic acid on the degradation of SF during storage. As shown in Figure 2, viscosity was nearly unchanged for $2 \mathrm{~d}$, indicating that SF molecules were relatively stable in formic acid without any severe degradation within experimental period.

Electrospinning generally produces the non-wovens of randomly arranged ultrathin fibers with nanometer scale diameters. Figure 3a shows SEM micrograph of the as-spun (i.e., untreated) SF nanofibers with magnification of 10000. The as-spun SF nanofibers exhibited a circular cross-section with a smooth surface. From the image analysis, they have an average diameter of $80 \mathrm{~nm}$ and their diameters ranged from 30 to $120 \mathrm{~nm}$, as shown in Figure $3 \mathrm{~b}$. This diameter corresponds to

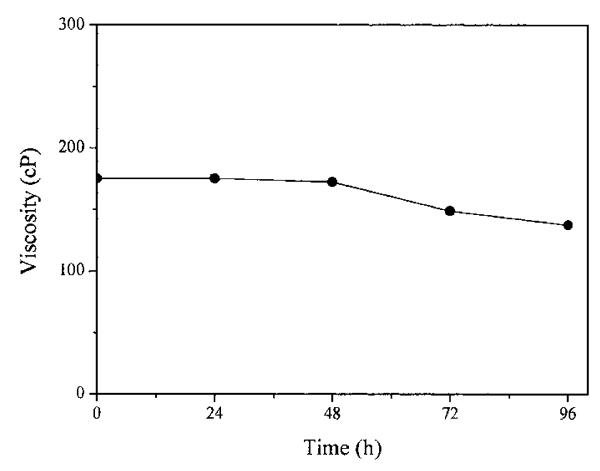

Figure 2. Viscosity of SF solution $v s$. storage times. 
(a)

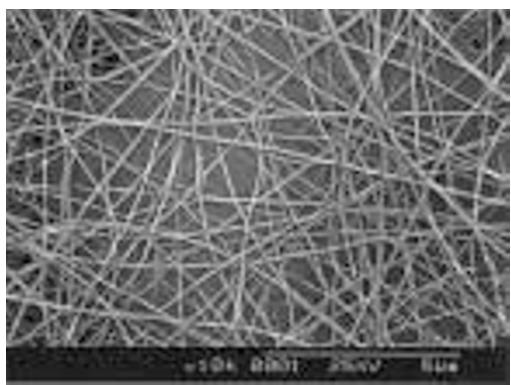

(b)

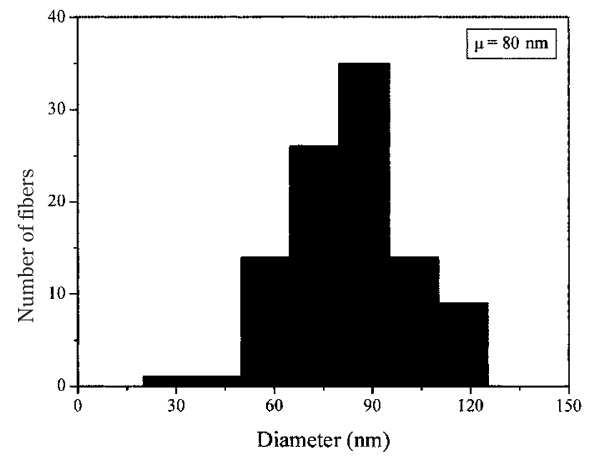

Figure 3. SEM image (a) and fiber diameter distribution (b) of electrospun SF nanofibers.

about two orders of magnitude smaller than raw silk fibroin fibers $(B$. mori $=10-20 \mu \mathrm{m})$. It was also noticeable that $30 \mathrm{~nm}$ fiber is only $\sim 60 \mathrm{SF}$ molecules wide, assuming a diameter of SF backbone as $5 \AA^{21}$

Pore properties of the as-spun and methanoltreated SF nonwovens were determined by a mercury porosimetry. The porosity of as-spun SF nanofiber nonwovens was $76.1 \%$, indicating it was highly porous. The total pore volume was $2.017 \mathrm{~mL} \mathrm{~g}^{-1}$. Figure 4 represents the variation in porosity and pore diameter of SF nonwovens with methanol-treating time. During the methanol treatment for $60 \mathrm{~min}$, porosity and pore volume of nonwovens composed of SF nanofibers decreased from $76.1 \%$ to $68.1 \%$ and 2.017 to $1.395 \mathrm{~mL} \mathrm{~g}^{-1}$, respectively, indicating that SF nonwovens somewhat shrunk by methanol treatment. Pore size of as-spun SF nonwovens had a maximum at about $220 \mu \mathrm{m}$, while that of the methanol-treated SF nonwovens had a maximum at about $190 \mu \mathrm{m}$. In addition, the amount and distribution of pores in the methanoltreated SF nonwovens became smaller and broader, respectively.

\section{Secondary Structure of Electrospun SF Nanofibers}

The physicochemical properties of SF fibers strongly depend on its molecular conformation or crystallinity. SF exhibits at least three conformations: random coil, silk I, and silk II. All three conformations can be formed by the appropriate preparation conditions and each is interchangeable under certain conditions. ${ }^{1}$ (a)

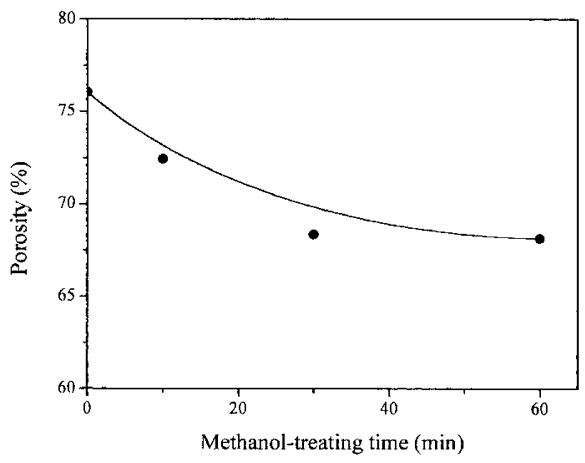

(b)

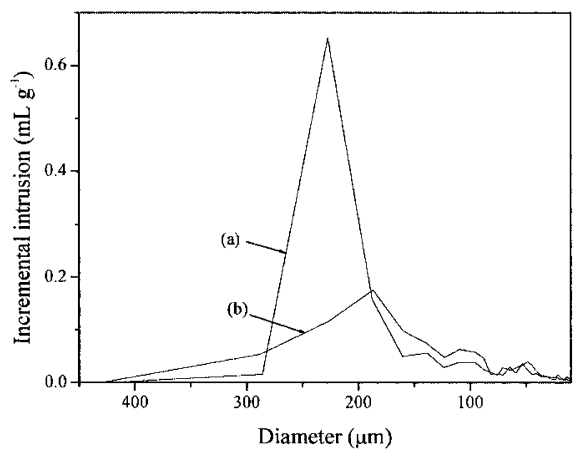

Figure 4. Variation in porosity (a) and pore diameter (b) of SF nonwovens with methanol treatment.

Crystallization of SF involved the conformational transition can be easily induced by simple physical (thermal), mechanical or chemical treatments. The most common method to convert the random coil or silk I conformation of SF into the more stable $\beta$-sheet (silk II) one is to treat the SF film by an organic solvent. It is well known that organic solvent, particularly methanol, is highly effective in the crystallization of SF from random coil or silk I to $\beta$-sheet. Therefore, we investigated the influence of the methanol treatment on the secondary structure of as-spun SF nanofibers by means of ATR-IR, WAXD, and solid-state CP-MAS ${ }^{13} \mathrm{C}$ NMR.

IR spectroscopy has been often applied to study the molecular conformation of silk fibroin fibers or films. The sensitive absorption bands on IR spectrum were located in the spectral regions of $1625 \mathrm{~cm}^{-1}$ (amide I), $1528 \mathrm{~cm}^{-1}$ (amide II), $1260 \mathrm{~cm}^{-1}$ (amide III), and $700 \mathrm{~cm}^{-1}$ (amide V) modes. To characterize the structure of SF nanofibers, we examined the ATR-IR spectra in the amide I and II regions. IR spectra of SF samples are shown in Figure 5a-c. The as-spun SF sample was characterized by absorption bands at 1651 (amide I) and $1528 \mathrm{~cm}^{-1}$ (amide II), attributed to the random coil conformation. The methanol-treated electrospun SF nanofibers showed strong $\beta$-sheet absorptions at 1623 and $1515 \mathrm{~cm}^{-1}$, irrespective of methanoltreating time from 10 to $60 \mathrm{~min}$. The crystalline structure of SF nanofibers treated with methanol solution for $10-60$ min was studied by X-Ray diffractometry. Fig- 


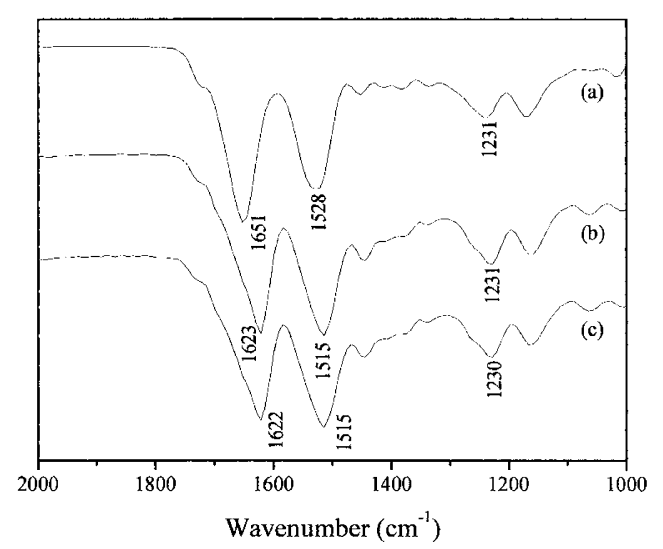

Figure 5. ATR-IR spectra of the electrospun and methanoltreated SF nanofibers: (a) as-spun; (b) treating time, $10 \mathrm{~min}$; (c) treating time, $60 \mathrm{~min}$.

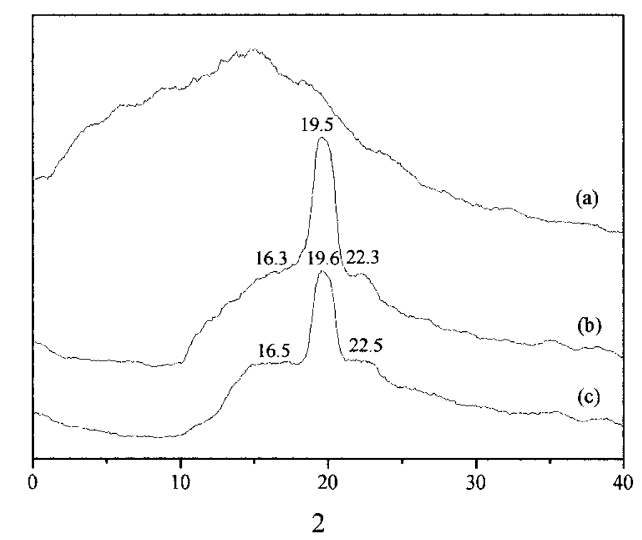

Figure 6. X-Ray diffraction curves of the electrospun and methanol-treated SF nanofibers: (a) as-spun; (b) treating time, $10 \mathrm{~min}$; (c) treating time, $60 \mathrm{~min}$.

ure $6 \mathrm{a}-\mathrm{c}$ shows the X-Ray diffraction curves of the SF nanofibers. The as-spun SF nanofibers showed no obvious $2 \theta$ peak, indicating that the SF conformation in the as-spun state was mainly random coil. However, methanol-treated samples exhibited a major diffraction peak at $19.5^{\circ}$ and two minor peaks at $16.5^{\circ}$ and $22.5^{\circ}$, respectively, corresponding to the $4.55,5.37$, and $3.98 \AA$ spacing, which are characteristics of the $\beta$-sheet crystalline structure. These results were consistent with those of IR spectroscopy. On the other hand, the conformational transition of the as-spun SF nanofibers into $\beta$-sheet was very fast and was almost completed within 10 min, compared with the regenerated SF film. This behavior can be explained by a higher surface area of nonwovens composed of SF nanofibers.

Solid-state ${ }^{13} \mathrm{C}$ NMR has been shown to be more effective analytical tool for demonstrating formation of $\beta$-sheets in polypeptides and proteins, because the isotropic ${ }^{13} \mathrm{C}$ NMR chemical shifts of carbon atoms in proteins are sensitive to the secondary structure. It is well established that SF take several kinds of conformations depending on the species of silkworms and condi-

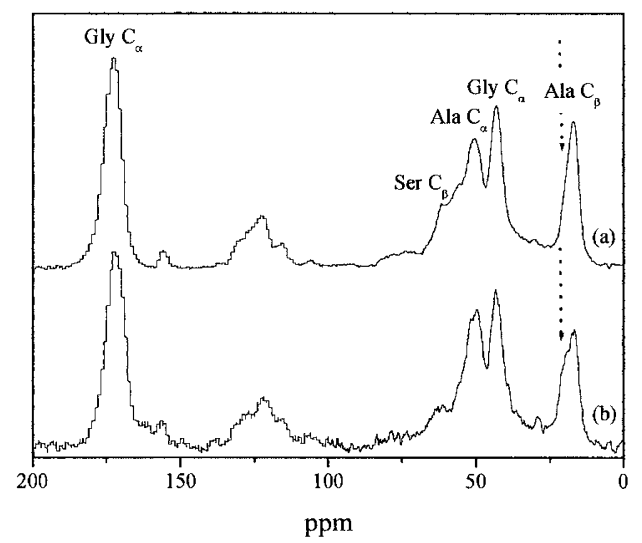

Figure 7. ${ }^{13} \mathrm{C} \mathrm{CP} / \mathrm{MAS}$ NMR spectra of (a) lyophilized SF sponge and (b) as-spun SF nanofibers. The dotted arrow indicates the chemical shift of alanine in the $\beta$-sheet conformation.

tions of sample preparation. ${ }^{22}$ In particular, it has been reported that fibroin from $B$. mori adopts two dimorphic structures, silk I and silk II. ${ }^{23}$ The silk II form is identified by the ${ }^{13} \mathrm{C}$ chemical shifts of Gly (glycine), Ser (serine), and Ala (alanine) that are indicative of $\beta$ sheets, while the silk I form produces chemical shifts that are associated with a loose helix. However, the less stable silk I is relatively unresolved structure, compared with silk II, and the conformation of the soluble form of SF that rapidly undergoes a transition to the insoluble silk II conformation. ${ }^{1}$ In ${ }^{13} \mathrm{C} \mathrm{CP} / \mathrm{MAS}$ NMR structural analyses of $B$. mori silk fibroins, the two crystalline forms of silk fibroins, silk I and silk II ( $\beta$-sheet), have been distinguished by the conformationdependent ${ }^{13} \mathrm{C}$ chemical shifts of the respective amino acid residues. ${ }^{24-27}$ Figure 7 shows solid-state ${ }^{13} \mathrm{C}$ NMR spectra of the as-spun SF nanofibers together with that of the lyophilized SF. Assignments were made according to the literature. ${ }^{26}$ Relationships between conformation and ${ }^{13} \mathrm{C}$ chemical shift have been well established for Ala, which is a major constituent of $\mathrm{SF}^{22}$ The chemical shifts of Ala residue were $17.6 \mathrm{ppm}$ for methyl group of Ala residues $\left(\right.$ Ala $\left.C_{\beta}\right), 49.9 \mathrm{ppm}$ for Ala $\mathrm{C}_{\alpha}, 173.5 \mathrm{ppm}$ for $\mathrm{Ala} \mathrm{C}=\mathrm{O}$ carbon. These chemical shift data indicate that the Ala residue take mainly non $\beta$-sheet conformation (random coil and silk I). The arrow in Figure 7 shows the chemical shift of Ala in the $\beta$-sheet conformation. It was noticeable that a shoulder at $\sim 20.4 \mathrm{ppm}$ assigned to Ala $\mathrm{C}_{\beta}$ in a $\beta$-sheet conformation was detected, indicating that as-spun SF nanofibers take some $\beta$-sheet conformation. This can be understood as follows. The electric positive charges are carried by the ejected jet on electrospinning. Therefore, the elongational force was imposed on the jet due to the electrostatic repulsion of the excess charge. ${ }^{28}$ The $\beta$-sheet structure of as-spun SF nanofibers could be partially formed by the elongational force. 


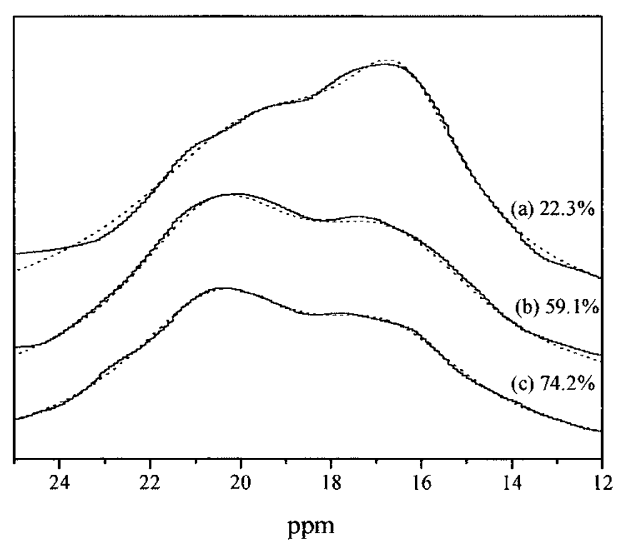

Figure 8. Expanded ${ }^{13} \mathrm{C}$ NMR spectra of the methyl alanine region for the electrospun and methanol-treated SF nanofibers: (a) as-spun; (b) treating time, $10 \mathrm{~min}$; (c) treating time, $60 \mathrm{~min}$. The full and dotted lines indicate the obtained and calculated spectra, respectively. The numbers in $\%$ on the each spectrum are the calculated content of Ala residues found $\beta$-sheet conformations.

Figure $8 \mathrm{a}-\mathrm{c}$ shows the expanded views of the methyl regions of Ala for regenerated, as-spun and methanoltreated SF nanofibers. The peak centered at $\sim 20.4 \mathrm{ppm}$ was assigned to Ala $C_{\beta}$ in a $\beta$-sheet conformation, while the one at $17.6 \mathrm{ppm}$ is attributed to side chains in non $\beta$-sheet structures. ${ }^{26}$ As can be seen in the Figure 8, the as-spun SF nanofibers [Figure 8a] has a strong signal from the region near $17.6 \mathrm{ppm}$ with shoulder at $20.4 \mathrm{ppm}$, while the next two spectra, Figure $8 \mathrm{~b}$ and c, have higher signal at $20.4 \mathrm{ppm}$. These data clearly indicate that the Ala residues in SF molecular chain took $\beta$-sheet structure. Therefore, the sequence of the expanded spectra region shows that SF molecules undergo significant conformational transitions during the aqueous methanol treatment. The dotted lines in Figure 8 are the calculated spectra using the two Gaussians, whose parameters were used to calculate the $\beta$-sheet content. The ratio of the area of the peak at $20.4 \mathrm{ppm}$ to the total area of the peaks at 20.4 and $17.6 \mathrm{ppm}$ is the content of Ala residues in the SF that reside in the $\beta$-sheet conformations. Figure 9 displays the relationship between the $\beta$-sheet content of Ala residues and the methanol treating time. It can be concluded that the conformational transition to $\beta$-sheet form occurred rapidly within $10 \mathrm{~min}$, and thereafter $\beta$-sheet content increased slightly.

\section{CONCLUSIONS}

The electrospinning of regenerated SF was performed with formic acid as a spinning solvent. The asspun SF nanofibers had an average diameter of $80 \mathrm{~nm}$ and their diameters ranged from $20 \mathrm{~nm}$ to $130 \mathrm{~nm}$. We investigated the influence of the methanol treatment on

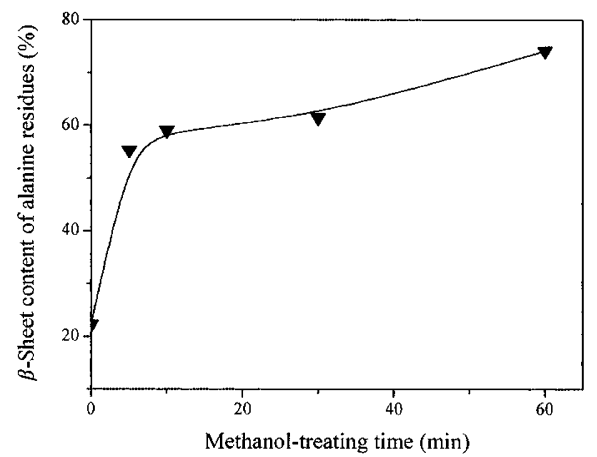

Figure 9. Relation between the $\beta$-sheet content of alanine residues and methanol-treating time.

the secondary structure of as-spun SF nanofibers by means of ATR-IR, WAXD, and solid-state CP-MAS ${ }^{13} \mathrm{C}$ NMR. Comparing with the regenerated SF film, conformational change of the as-spun SF nanofibers into $\beta$-sheet was very fast and was almost completed within $10 \mathrm{~min}$. This behavior can be explained by a higher surface area of nonwovens composed of nanofibers. From the solid-state CP-MAS ${ }^{13} \mathrm{C}$ NMR spectra, it can be concluded that the conformational change occurred rapidly within $10 \mathrm{~min}$, and thereafter $\beta$-sheet content increased slightly.

Acknowledgment. This work was supported by Korea Research Foundation Grant (KRF-2001-005E00037).

\section{REFERENCES}

1. D. Kaplan, W. W. Adams, B. Farmer, and C. Viney, Ed., "Silk Polymers: Materials Science and Biotechnology", American Chemical Society, Washington DC, D.C., 1994.

2. M. Li, S. Lu, Z. Wu, K. Tan, N. Minoura, and S. Kuga, Int. J. Biol. Macromol., 30, 89 (2002).

3. T. Asakura, M. Kitaguchi, M. Demura, H. Sakai, and K. Komatsu, J. Appl. Polym. Sci., 46, 49 (1992).

4. M. Demura and T. Asakura, Biotech. Bioeng., 33, 598 (1989).

5. S. Putthanarat, S. Zarkoob, J. Magoshi, J. A. Chen, R. K. Eby, M. Stone, and W. W. Adams, Polymer, 43, 3405 (2002).

6. H. Sakabe, H. Ito, T. Miyamoto, Y. Noishiki, and W. S. Ha, Sen-i Gakkaishi, 45, 487 (1989).

7. W. H. Park, W. S. Ha, H. Ito, T. Miyamoto, H. Inagaki, and Y. Noishiki, Fibers and Polymers, 2, 58 (2001).

8. M. Santin, A. Motta, G. Freddi, and M. Cannas, J. Biomed. Mater. Res., 46, 382 (1991).

9. P. Gibson, H. Schreuder-Gibson, and D. Rivin, Colloids Surf., A, 187, 469 (2001).

10. W. Li, C. T. Laurencin, E. J. Caterson, R. S. Tuan, and F. K. Ko, J. Biomed. Mater. Res., 60, 613 (2002).

11. E. D. Boland, G. L. Bowlin, D. G. Simpson, and G. E. Wnek, PMSE Preprints, 85, 51 (2001).

12. S. A. Athreya, and D. C. Martin, Sen. Actuators, 72, 203 (1999). 
13. X. Wang, S. Lee, C. Drew, K. L. Senecal, J. Kumar, and L. A. Samuelson, PMSE Preprints, 85, 617 (2001).

14. M. Bognitzki, H. Hou, M. Ishaque, T. Frese, M. Helling, C. Schwarte, A. Schaper, J. H. Wendorff, and A. Greiner, $A d v$. Mater., 12, 637 (2000).

15. R. A. Caruso, J. H. Schattka, and A. Greiner, Adv. Mater., 13, 1577 (2001).

16. R. L. Lock, U.S. Patent 5252 285, (1993).

17. K. A. Trabbic and P. Yager, Macromolecules, 31, 462 (1998).

18. O. Liivak, A. Blye, N. Shah, and L. W. Jeinski, Macromolecules, 31, 2947 (1998).

19. S. Zarkoob, D. H. Reneker, R. K. Eby, S. D. Hudson, D. Ertley, and W. W. Adams, Polym. Prepr. (Am. Chem. Soc., Div. Polym. Chem.), 39, 244 (1998).

20. A. Seidel, O. Liivak, S. Calve, J. Adaska, G. Ji, Z. Yang, D. Grubb, D. A. Zax, and L. W. Jelinski, Macromolecules, 33,
$775(2000)$.

21. L. Stryer, Ed., "Biochemistry", W. H. Freeman and Company, New York, N.Y., 1988.

22. H. Saito, R. Tabeta, T. Asakura, Y. Iwanaga, A. Shoji, T. Ozaki, and I. Ando, Macromolecules, 17, 1405 (1984).

23. H. Saito, Mag. Reson. Chem., 24, 835 (1986).

24. T. Asakura, A. Kuzuhara, R. Tabeta, and H. Saito, Macromolecules, 18, 1841 (1985).

25. T. Asakura, T. Ito, M. Okudaira, and T. Kameda, Macromolecules, 32, 4940 (1999).

26. T. Asakura, M. Demura, T. Date, N. Miyashita, K. Ogawa, and M. P. Williamson, Biopolymers, 41, 193 (1998).

27. T. Asakura, M. Iwadate, M. Demura, and M. P. Williamson, Int. J. Biol. Macromol., 24, 167 (1999).

28. X. Zong, K. Kim, D. Fang, S. Ran, B. S. Hsiao, and B. Chu, Polymer, 43, 4403 (2002). 